\title{
Training of the future mathematics teachers to form their students' health-preserving competence by means of ICT
}

\author{
T. Hodovaniuk, T. Makhometa, I. Tiahai, D.Voznosymenko, V. Dubovyk
}

Pavlo Tychyna Uman State Pedagogical University, 2 Sadova st., 20300, Uman, Cherkasy Region, Ukraine Corresponding author. E-mail: tgodovanyuk@ukr.net, tetiana.makhometa@gmail.com,i.m.tiagai@gmail.com, daryakholod@ukr.net, vitalij.dybovuk@gmail.com

Paper received 03.11.21; Accepted for publication 22.11.21.

\section{https://doi.org/10.31174/SEND-PP2021-259IX101-03}

\begin{abstract}
The article describes the features of the use of information and communication technologies (ICT) in the preparation of the future teachers of mathematics for the formation of health-preserving competence of their students. In particular, it is noticed that one of the effective means of preparing future teachers of mathematics for the health preserving awareness of their students in the learning process is the use of e-manuals, namely the developed e-manual «Collection of valeologically themed mathematics problems for the students of the 5-9 grades». The use of the e-manual in the process of methodical teacher training opens new opportunities in the organization of the educational process of students, promotes the development of independent work skills, students' creative abilities.

Keywords: Information and computer technologies, future Mathematic teachers, electronic manual, valeological competence.
\end{abstract}

Introduction. Changes in the system of higher education in Ukraine are aimed at the rapid development of modern information and communication technologies (ICT). Only the members of society who have the necessary knowledge, skills and abilities allowing practical interaction in the information space, quickly adapt to modern information and communication tools, and generally have an information technology culture to meet their personal and professional needs can successfully use ICT. The ability to work quickly, efficiently and effectively work with data, using modern tools and methods is becoming more important [13].

Requirements to professional training of the teachers considerably increase in the conditions of wide use of means of information technology in educational process. Due to this, it makes sense to use ICT as one of the effective means of implementing new educational paradigms, contributing to the formation of a competent teacher that can work in a dynamic information space in the process of higher education institutions.

Information society provides the latest tools for assisting forming the new generation of teachers, who are capable of not merely organizing the learning process with the help of the computer, but assure their students' education is directed in a way that promotes their health awareness and their health preserving motivation and motivation to lead healthy lifestyles.

Therefore, to keep up with the innovations, pedagogic training establishments need to train a creative, welleducated professional, a mathematics teacher in this case, that could not only teach mathematics to his students using ICT, but teach them healthy lifestyle and respect to and wholesome treatment of their bodies, health and environment.

Integration of the information and communication technologies in the primary process of higher education allows for expanding the future professionals' knowledge, encourages active learning, increases curiosity and cognitive motivation, and helps increase interest in learning.

According to V. Godlevskaya, Y. Kobyuk, [1, p. 4], the use of ICT in vocational education increases the effectiveness of training of the future professionals, encourages a fundamentally new way of learning, directs the student to consciously acquire knowledge in the process of performing pedagogical tasks, forms independence at the initial stages of higher education.

Analysis of recent research and publications. Many theoretical and experimental studies are devoted to the problem of using ICT in the educational process. In particular, the features and prospects of the use of ICT in the educational process and their didactic possibilities are covered in the studies of V. Bykov [2], T. Vakalyuk [3], V. Grigoreva [4], R. Gurevich [5], Y. Zhuk [6 ], N. Tverezovskaya [7], and others.

The use of ICT in the educational process is the subject of research by many foreign scholars, such as D. Daniel, W. Woody [8], MP Galindo-Villardon ), M. K. PatinoAlonso [9], K. A. Collazos, F. Moreira, M. Ramirez [10], J. Luximon, K. Sheen [11], R. Stone [12] and others.

At the present stage of development of society under the influence of environmental, economic and social factors, the problem of preserving and strengthening the health of the younger generation is especially relevant. Exacerbation of health and demographic problems, the state of health of the human body is the subject of empirical and applied research in many fields. The works of Yu. Boychuk [13], G. Zhara [14], N. Pyasetska [15], I. Shcherbyna [16] and others are devoted to the problem of training of the future teachers for health-preserving activities.

The research of O. Homonyuk deserves special attention among the research about the use of information and communication technologies in the training of future teachers in the context of our topic. In his study «The importance of information and communication technologies in the formation of valeological competence of the future teachers» [17] the author notes that to achieve high learning efficiency and the formation of high-quality of health-preserving competence of the future teachers one must purposefully ensure the use of information and communication technologies. This will significantly affect their motivation and ensure the success of mastering professional knowledge and skills. We completely agree with the author. However, it is necessary to not only solve the problem of forming of the health-preserving competence of the teacher, but also form of the methodological competence of the subject teachers, to assure they can use the potential of teaching their subjects in a way the health 
competence of their students is formed. Thus, the problem of preparing the future teacher of mathematics for the formation of health-preserving competence of students, in particular by means of ICT, is not sufficiently studied and requires further research.

The purpose of the article is to reveal the methodological features of the use of ICT in the preparation of the future mathematics teachers for the formation of healthpreserving competence of their students.

Methods of the study. Methods used in the research process include: analysis of theoretical sources, generalization of best pedagogical practices of foreign and domestic specialists of using the electronic manuals in the learning process of students; synthesis, generalization and conceptualization for the development of the main research provisions; interviewing students; generalization of results.

Results. One of the main directions of education development in Ukraine is the formation of a healthy lifestyle in the younger generation. State policy aimed at providing appropriate conditions for the development of a healthy personality of the student in every institution of general secondary education is implemented primarily through the educational activities of teachers. Thus, environmental literacy and healthy living is one of the $10 \mathrm{key}$ competencies that should be formed in students during their time in school as per the Concept «New Ukrainian School» [18]. In particular, the curricula for general secondary education state that the task of the cross-cutting lines of key competencies «Health and Safety» is to form a student as an emotionally stable member of the society, able to lead a healthy lifestyle and create a safe living environment.

Accordingly, the problem of preparing students for the formation of their students' health-preserving competence, in particular by means of ICT, deserves special attention in the preparation of the future mathematics teachers for their professional activity.

One of the effective ways to prepare future math teachers for developing of the health-preserving awareness of their students in the learning process is to use electronic manual (also e-manual). Definitions of emanual in scientific publications are very diverse:

- a universal interactive hypermedia methodical and didactic textbook, containing a wide range of topics of one discipline (or different disciplines), presented in a compact form of hypertext environment, and is intended for be used in the learning process [19, p. 206].

- a curriculum-methodical complex designed to help students to master the course or its section independently or with the help of a teacher [20].

- an electronic publication designed to assist in practical activities or in mastering the discipline, the material in which is presented in a convenient for study and teaching form, which has undergone editorial and publishing processing, intended for distribution in the same form, contains the original data [21].

According to S. Sysoeva, an e-manual is a curriculummethodical complex that allows for independent study of a particular course or section, which combines the qualities of a textbook, reference book, collection of tasks. The researcher also emphasizes that it is an alternative to traditional teaching aids and can be combined (if pedagogi- cally appropriate) with a computer utilizing the advantages of the latter [22, p.163].

M. Kademiya and O. Shestopalyuk, believe that emanuals can be considered an additional teaching tool that allows for methodically correct organization of independent work, diversification of the practical classes, developing skills and abilities of the student audience [23].

According to the new mathematics curriculum identifying a number of key competencies and indicating a cross-cutting line «Health and Safety», methodical preparation of the future mathematics teachers for developing of the health competency of their students in the classroom requires these pedagogical students to learn methods of working with math problems from the grade school mathematics curriculum, in particular, problems of health-preserving content.

Taking into account the advantages of using e-manual in the process of implementing of the educational process, we have developed an e-manual «Collection of valeologically themed mathematics problems for the students of the 5-9 grades», employing AutoPlayMediaStudio8.0.7.0 platform.

AutoPlayMediaStudio8.0.7.0 was used to create an emanual «Collection of valeologically themed mathematics problems for the students of the 5-9 grades». This platform is a powerful visual package suited for fast and high-quality development of AutoRun-menus, interactive presentations, multimedia applications and more. With the help of this program one can create all the necessary files for autorun of the e-manual and its interface and use a wide range of options, tools and settings for software development. Using AutoPlay Media Studio allowed to fully implement the structure of the e-manual with an attractive interface and multimedia content. The proposed e-manual is aimed at:

- formation of professional, mathematical and health competencies;

- mastering the theory and practice of teaching both: mathematical content and the content related to health preservation;

- determining the range of possibilities mathematics as a subject has for the formation of a healthy lifestyle.

Thus, in laboratory classes on methods of teaching mathematics, students should be asked to, using the emanual «Collection of valeologically themed mathematics problems for the students of the 5-9 grades», develop a fragment of a lesson on one of the topics of the school mathematics curriculum to illustrate the possibility to implement the cross-cutting lines of key competencies «Health and Safety». When using the e-manual, future teachers should realize that solving problems with specific health content should evoke positive emotions in students to both, studying mathematics and the situation described in the problems. Using e-manual in such situations should also expand the life experience of their students, promote the formation of social and spiritual health of their students, develop their aesthetic and moral qualities, promote valeologically sound decisions, making mathematics more personable for the students. Accordingly, the tasks presented in the e-manual meet certain methodological requirements, namely:

- reflecting reality, carrying cognitive information from the relevant field, containing real numerical data and have 
realistic solutions;

- the condition of the problem is concise, not overloaded with various information;

- the problem are of, primarily, mathematical essence.

In addition to valeological tasks, the e-manual contains useful information in a form of reference material (scientific facts, statistics, etc.), and when one clicks on the «Video Info" button, videos containing up-to-date health information, including that of preventive nature open.

Organizational and technological possibilities of the manual's application are due to, first of all, the opportunity to work in various modes. Students can get acquainted with the methods of working on health problems, which can be used in the preparation and teaching of mathematics lessons. Additionally, students can study at a convenient time, place and pace when using this e-manual. Another feature of this e-manual is that it can also be used by students as a guide and as a simulator. In particular using this e-manual helps saving the teacher's time by finding the necessary material for the lesson.

If the lesson requires, other modern technologies, in addition to the hyperlinks in the e-manual, can be used for quick access to information from the network. Therefore, the use of QR codes deserves attention. It can encode a variety of content elements: video from a site, a social networks account, phone number, and so on.
For example, students can be asked to:

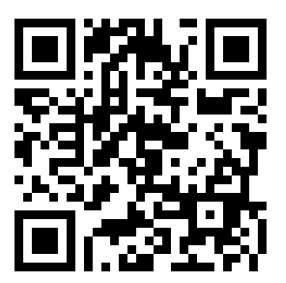

Fig. 1. Example of a QR-code

- encode a link that directs students to an educational site with health information helpful for the solving of the problems;

- place such codes on information boards;

- use the QR-code directly in the practice lesson in the form of coded evaluation tasks or tests to test their students' knowledge of the material, etc.

Figure 1 shows an example of a QR-code created by students in a laboratory lesson on methods of teaching mathematics. It encrypts the task for the 6th grade students on the topic «Percentage». After reading the code, students gain access to an interactive exercise developed in the LearningApps.org environment (Figure 2, Figure 3, Figure 4).

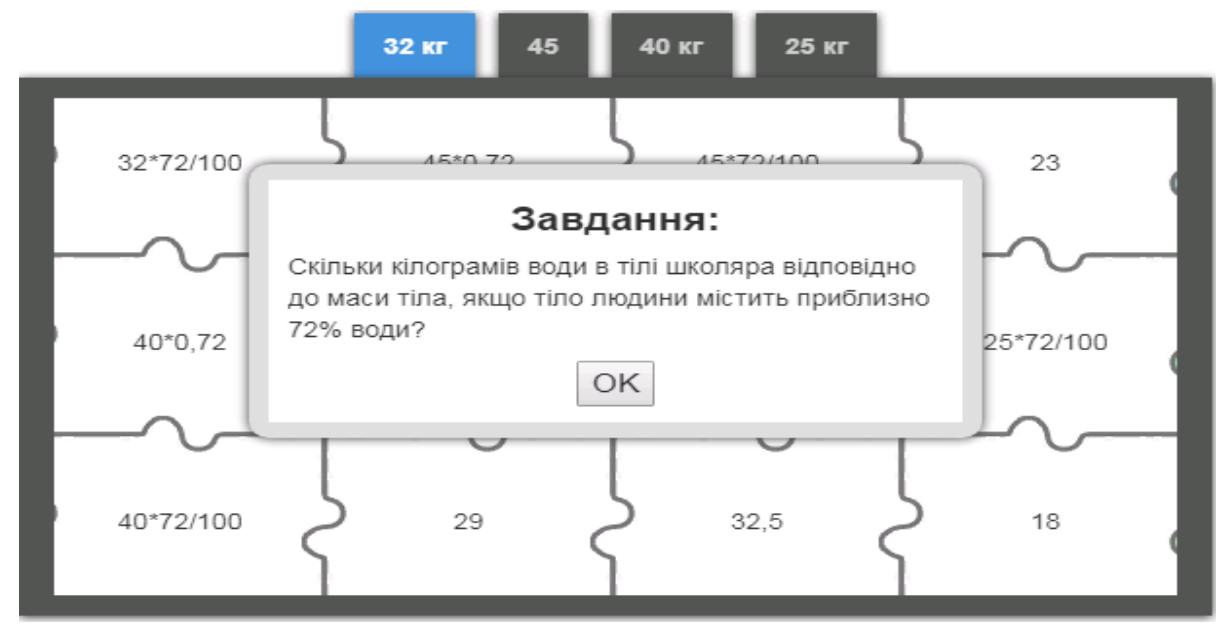

Fig. 2. Example of a coded task

\begin{tabular}{|l|l|l|l|}
$32 \mathrm{kr}$ & 45 & $40 \mathrm{kr}$ & $25 \mathrm{kr}$ \\
\hline
\end{tabular}

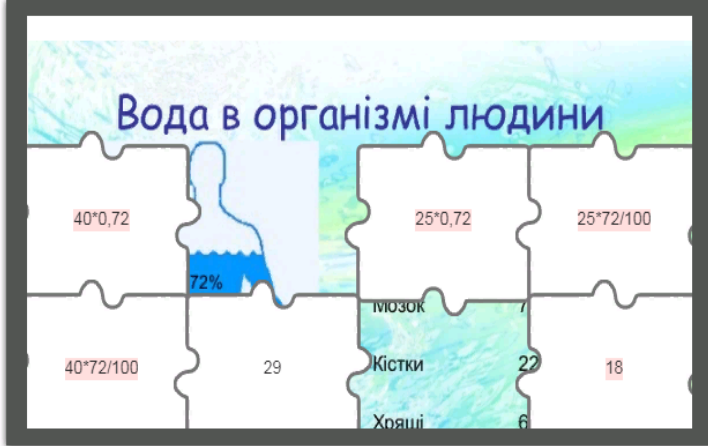

Fig. 3. Example of a coded task

In the process of teaching mathematics, it is important to monitor student performance and assess the level of their academic achievement. Nowadays, the modern education system requires teachers to use innovative methods

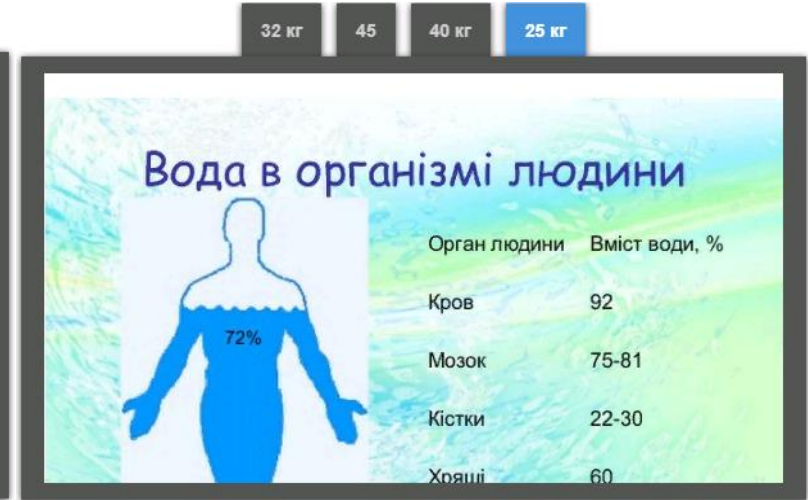

Fig. 4. Example of a coded task

and approaches along with traditional methods of assessing acquired knowledge and competencies. Such methods include various forms of testing, self-assessment and peer review letters, work diaries, etc. 
One can conduct testing using the above-mentioned service LearningApps.org. However, the exercise patterns provided by this program somewhat limit the range of the skills to test. In addition, in our opinion, this environment is better suited for face-to-face work in a classroom. Therefore, in order to assess an individual student's performance, it is advisable to suggest that the future math teachers should use local testing services. EasyQuizzy program is quite successful developing test with health competence content for the topics of the school mathematics course. Below is a fragment of a test developed by students on the topic of "Percentage" for the 5th grade students the e-manual contains (Fig. 5).

The program allows for designing test assignments of different types, adding graphics and formulas, setting time limits for the test. Students can choose to use a rubric or apply their own measure. Upon completion of the test, the student immediately receives a final report. It is very convenient that the procedure of saving the test creates an independent program that can be copied to any computer.

ICT features used in the training of future mathematics teachers allow students to obtain knowledge, skills and abilities to develop an adequate attitude of students to their health, to positively perceive educational, health, preventive measures and more.

After teaching classes on methods of teaching mathematics using e-manuals and other ICT tools, students were interviewed about the interest, user experience and effectiveness of ICT in the process of forming students' health competence.

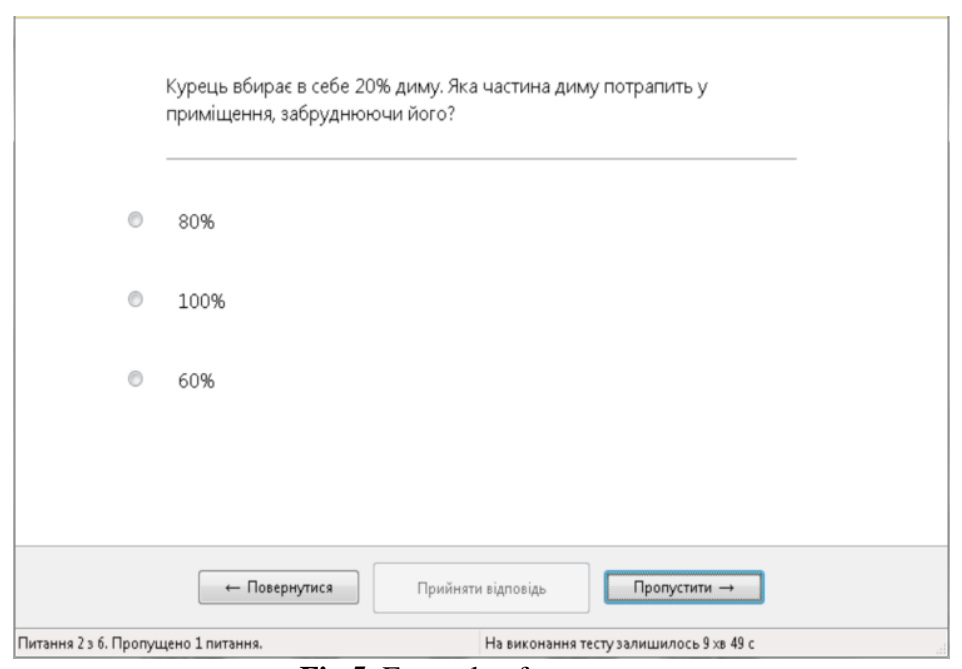

Fig.5. Example of test

34 students of the Faculty of Physics, Mathematics and Informatics of Pavlo Tychyna Uman State Pedagogical University took part in the survey. The results of the survey are presented in Figures 4 and 5.

Almost $100 \%$ positive results said that they considered the e-manual «Collection of valeologically themed mathematics problems for the students of the 5-9 grades» comprehensive and user friendly.

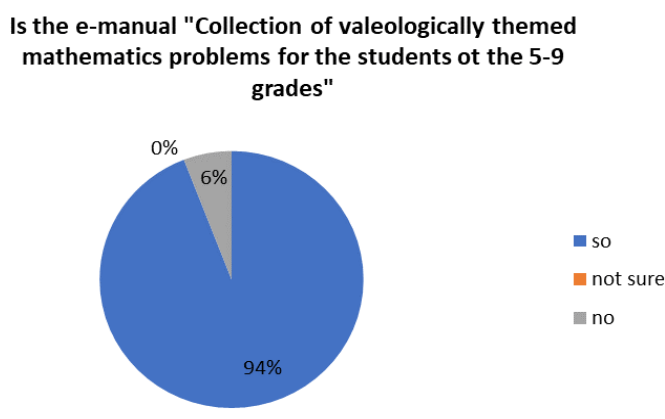

Fig.6. The results of a students' survey

Additionally, according to the students, they plan to use this e-manual in the process of forming students' health competence in their future professional activity.

The results of the conducted research confirm the hypothesis of the effectiveness of the use of various ICT tools, including e-manual, in the process of developing health-preserving competence of students. Systematic testing of ICT in the process of preparation of future mathematics teachers to the implementation of crosscutting lines of key competencies «Health and Safety» will promote the students development of health competence in their students.

Conclusions. The information society makes new demands on the modern teacher: it is the ability to navigate a large amount of information, to use ICT in professional activities, the desire for innovation, self-education and self-development. Therefore, in the course of the research
Do you plan to use the e-manual "Collection of valeologically themed mathematics problems for the students ot the 5-9 grades" in the process of forming students' health-preserving competence?

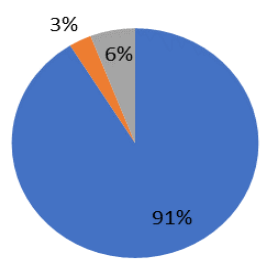

no

not sure

Fig.7. The results of a students' survey

the educational-methodical and scientific literature, as well as Internet sources on the problem of using ICT in the preparation of future mathematics teachers for the implementation of valeological support of student learning were analyzed.

The use of e-manual in the process of methodical teacher training opens new opportunities in the organization of the educational process of students, promotes the development of independent work skills, creative abilities of students. The e-manual can be considered as one of the optimal means of preparing future mathematics teachers for the formation of students' health-preserving competence through ICT.

We see prospects for further research in the adaptation of software to prepare future teachers for the implementation of a cross-cutting line of key competencies «Health and Safety». 


\section{REFERENCES}

1. K. V. Godlevskaya, Yu. M. Kobyuk, Preparation of the future teacher for the use of information and communication technologies in professional activities, Kiev, 2016, 44 p.

2. V. Y. Bykov, Modern task information education, Information technology and learning tools: electronic scientific specialized edition / Inst inform. technology and training Sciences of Ukraine, Univ of Management Education Pedagogical Sciences of Ukraine, Ch. eds.: V. Bykov, 2010, № 1 (15).

3. T. A. Vakalyuk, YU. O. Konchakivs'kyy, Advantages of using electronic textbooks in educational institutions of Ukraine, Computer at school and family, no. 4, 2014, pp. 22-24. URL: http://nbuv.gov.ua/UJRN/komp_2014_4_7.

4. V. B. Hryhorieva, Methodical systems of teaching mathematics using ICT in the training of future teachers in the field of geometry, Information Technology in Education, Issue 18, 2014, pp. 139-148. URL: http://nbuv.gov.ua/UJRN/itvo_2014_18_18

5. R. S. Gurevich, G. B. Gordichichuk, L. L. Konoshevsky, O. L.Konoshevsky and O.V.Sheistopal, Educational environment for the training of future teachers by means of ICT: [monograph], Vinnitsa, Ukraine: FOP Rogalskaya IO, 2011.

6. YU. O. Zhuk, Theoretical and methodological principles of organizing the educational activities of high school students in a computer-based learning environment: [monograph], Kiev, Ukraine: Pedagogical thought, 2017.

7. N. T. Tverezovska, Didactic aspects of modernization of teaching aids in terms of informatization of education, Bulletin of Chernihiv National Pedagogical University. Pedagogical sciences, Issue 108(1), 2013. URL: http://nbuv.gov.ua/jpdf/VchdpuP_2013_1_108_32.pdf.

8. D. B. Daniel, W. D. Woody, «E-textbooks at what cost? Performance and use of electronic v. print texts», Computers \& Education, vol. 62, 2013, pp. 18-23. doi: 10.1016/j.compedu.2012.10.016

9. M. P. Galindo-Villardon, M. C. Patino-Alonso, M. C. VegaHernandez, «Multivariate characterization of university students using the ICT for learning», Computers \& Education, vol. $121, \quad 2018, \quad$ pp. 124-130. https://doi.org/10.1016/j.compedu.2018.03.004

10. C. Collazos, F. Moreira, G. Ramirez, «All-Learning: The state of the art of the models and the methodologies educational with ICT», Telematics and Informatics, Vol. 35, Issue 4, 2018, $\mathrm{pp}$.

944-953. https://doi.org/10.1016/j.tele.2017.10.004

11. K. A. Sheen, Y. Luximon, «Relationship between Academic Discipline and User Perception of the Future of Electronic Textbooks», Procedia Manufacturing, vol.3, 2015, pp. 58455850. https://doi.org/10.1016/j.promfg.2015.07.841
12. R. W. Stone, L. Baker-Eveleth «Students' expectation, confirmation, and continuance intention to use electronic textbooks», Computers in Human Behavior, vol. 29, Issue 3, 2013, pp. 984-990. https://doi.org/10.1016/j.chb.2012.12.007 13. Yu. Boichuk Ecological and valeological culture of the future teacher: theoretical and methodological aspects: [monograph], Sumy, Ukraine: «University Book», 2008.

14. G. I. Zhara, Preparation of future teachers for the formation of valeological concepts in students on the basis of interdisciplinary links of school natural courses: PhD diss. Science: Kyiv, 2009.

15. N. A. Piasetska, Formation of valeological culture of future teachers in higher educational institutions of I-II levels of accreditation: PhD diss: Kyiv, 2004.

16. Yu. Shcherbyna, Pedagogical conditions of preparation of future teachers for health-preserving education of pupils in comprehensive school: PhD thesis abstract. Cherkasy, 2017.

17. O. M. Homoniuk, The importance of information and communication technologies in the formation of valeological competence of future teachers, Collection of scientific papers, Vol. 1, Series: Pedagogical and psychological sciences, 2016, pp. 72-94,

18. New Ukrainian school: conceptual principles of secondary school reform.URL: https://www.kmu.gov.ua/storage/app/media/reforms/ukrainsk a-shkola-compressed.pdf

19. N. V. Kononets', Aspects of pedagogical mastery of the teacher: development of electronic manuals. The origins of pedagogical skills, № 6, 2009, pp. 202-210. URL: www.nbuv.gov.ua/portal/Soc_Gum/Vpm/2009_6/kononec

20. T. Napadii, N. Slabitska, Preparation and creation of an electronic manual. URL: http://gi.edu.ua/images/stories/vykladachu/prof_zros $\tan -$ na/shkola_vykladacha/skarbnychka/pidgotovka_do_stv_elakt ron_pidruchnykiv.pdf

21. N. M. Figol, Electronic Textbook or Manual: To the Problem of Definition in the Journal of the National. University Lviv Polytechnic: Series «Problems of Ukrainian Terminology», N. Chukhra, Ed. Lviv, Ukraine: No. 733, 2012, pp. 53-56

22. S. O. Sysoieva, T.I. Koval', L.P. Sushchenko, Training of higher school teachers: information technologies in pedagogical activity. Kyiv, 2009.

23. M. Yu. Kademiya, O. V Shestopalyuk, Electronic textbook on an interactive basis, Pedagogical discourse. URL: http://www.nbuv.gov.ua/portal/Soc_Gum/peddysk/200 7_02/kademiya.pdf 